\title{
The effects of pigment epithelium-derived factor on atherosclerosis: putative mechanisms of the process
}

\author{
Shouyuan $\mathrm{Ma}^{1+}$, Shuxia Wang ${ }^{2 \dagger}$, Man $\mathrm{Li}^{1}$, Yan Zhang ${ }^{1}$ and Ping Zhu ${ }^{1 *}$
}

\begin{abstract}
Cardiovascular disease (CVD) is a leading cause of death worldwide. Atherosclerosis is believed to be the major cause of $C V D$, characterized by atherosclerotic lesion formation and plaque disruption. Although remarkable advances in understanding the mechanisms of atherosclerosis have been made, the application of these theories is still limited in the prevention and treatment of atherosclerosis. Therefore, novel and effective strategies to treat high-risk patients with atherosclerosis require further development. Pigment epithelium-derived factor (PEDF), a glycoprotein with anti-inflammatory, anti-oxidant, anti-angiogenic, anti-thrombotic and anti-tumorigenic properties, is of considerable interest in the prevention of atherosclerosis. Accumulating research has suggested that PEDF exerts beneficial effects on atherosclerotic lesions and CVD patients. Our group, along with colleagues, has demonstrated that PEDF may be associated with acute coronary syndrome (ACS), and that the polymorphisms of rs8075977 of PEDF are correlated with coronary artery disease (CAD). Moreover, we have explored the anti-atherosclerosis mechanisms of PEDF, showing that oxidized-low density lipoprotein (ox-LDL) reduced PEDF concentrations through the upregulation of reactive oxygen species (ROS), and that D-4F can protect endothelial cells against ox-LDL-induced injury by preventing the downregulation of PEDF. Additionally, PEDF might alleviate endothelial injury by inhibiting the Wnt/ $\beta$-catenin pathway. These data suggest that PEDF may be a novel therapeutic target for the treatment of atherosclerosis. In this review, we will summarize the role of PEDF in the development of atherosclerosis, focusing on endothelial dysfunction, inflammation, oxidative stress, angiogenesis and cell proliferation. We will also discuss its promising therapeutic implications for atherosclerosis.
\end{abstract}

Keywords: Pigment epithelium-derived factor, Atherosclerosis, Coronary artery disease

\section{Background}

Cardiovascular disease (CVD) is responsible for the majority of morbidity and mortality worldwide, accounting for approximately one third of deaths globally $[1,2]$. Atherosclerosis and its cardiovascular ischemic complications are thought to be the major underlying cause of CVD, acute coronary syndrome (ACS) and stroke [3, 4]. Atherosclerosis is a chronic vascular disease with multiple factors and links and is characterized by atherosclerotic lesion disruption with superimposed thrombus formation [5]. This type of vascular pathology is chiefly involved in a

\footnotetext{
* Correspondence: zhuping301hospital@163.com

† Shouyuan Ma and Shuxia Wang contributed equally to this work.

'Department of Geriatric Cardiology, Chinese PLA General Hospital, Beijing

100853, China

Full list of author information is available at the end of the article
}

combination of endothelial dysfunction, extensive lipid deposition in the intima, enhanced immune responses, proliferation and migration of vascular smooth muscle cells (VSMCs), remodeling of the extracellular matrix (ECM), formation of fibrous caps, atherosclerotic plaque formation, plaque expansion and rupture, and thrombosis of the affected vessel [3]. Atherosclerosis primarily affects the medium and large arteries and causes serious, harmful cardiovascular ischemic events. Accumulated evidence has shown that the atherosclerotic process is typically initiated by endothelial dysfunction $[5,6]$. The infiltration of inflammatory cells and release of inflammatory mediators, oxidative stress, cell proliferation and vascular remodeling all play crucial roles in atherosclerosis [7-9]. These processes are the key mechanisms in the development of atherosclerosis [7]. 
Pigment epithelium-derived factor (PEDF) is of considerable interest due to its anti-inflammatory, anti-oxidant, anti-angiogenic, anti-thrombotic, anti-tumorigenic, neurotrophic and neuroprotective properties [10, 11]. PEDF has been shown to be pleiotropic and was first extracted from the medium of human fetal retinal pigment epithelium (RPE) [12]. It belongs to the serine protease inhibitor (SERPIN) supergene family, located on chromosome 17p13.1 [13]. A great deal of research has been carried out to elucidate the role of PEDF in cardiovascular physiology and pathophysiology, such as in ischemic heart disease, atherosclerosis and ACS [10]. It has been suggested that, along with brain natriuretic peptide (BNP), PEDF concentrations may be a valuable marker for heart failure (HF) prognosis [14]. In addition, PEDF plasma concentrations were closely associated with blood pressure and could predict incident hypertension [15]. The substitution or upregulation of PEDF through the use of medication may prevent and treat occlusive thrombus [16]. Furthermore, Yamagishi S and his colleagues [17] have reported that PEDF could suppress $\mathrm{NADPH}$ oxidase-mediated reactive oxygen species (ROS) generation and may play an important role in the development and progression of atherosclerosis. Importantly, serum level of PEDF is believed to be a marker of atherosclerosis in humans [18]. Additionally, our group has carried out recent studies on PEDF, ranging from clinical issues to molecular mechanisms. Initially, we found that plasma PEDF level was significantly lower in ACS patients, and lower PEDF level was associated with adverse cardiac outcomes after ACS [19]. Furthermore, our data showed that plasma PEDF level was significantly lower in CAD patients and PEDF may be used as a potential predicator for coronary severity [20]. An analysis of single nucleotide polymorphisms (SNPs) suggested that the $\mathrm{T}$ allele of rs8075977 in the $5^{\prime}$-flanking region of the PEDF gene may be protective for coronary artery disease (CAD) [21]. For these reasons, we have undertaken further investigations. One of the key factors of atherosclerosis, oxidized-low density lipoprotein (ox-LDL), was shown to reduce PEDF through the upregulation of ROS [22]. D-4F can protect endothelial cells (ECs) against ox-LDL-induced injury by preventing the downregulation of PEDF [23]. Moreover, our group found that PEDF might alleviate endothelial injury by inhibiting the Wnt/ $\beta$-catenin pathway [24]. Therefore, the effects of PEDF have gained much importance in their relation to the major processes in atherosclerosis, such as endothelial dysfunction, inflammation, and oxidative stress, among others. In this review, the current understanding of PEDF will be described and its role in atherosclerosis and pivotal pathophysiologic activities will be highlighted.

\section{Overview of PEDF}

PEDF is a $50 \mathrm{kDa}$ secreted, pleiotropic glycoprotein. This protein shares sequence and structural homology with SERPIN family proteins but does not inhibit proteases
[25]. Many organs in the human body naturally express PEDF, such as the eye, liver [26], brain [27], pancreas [28], bone [29], adipose tissue and spinal cord [29]. Additionally, PEDF is present in the human heart [30, 31]. As an endogenously produced, extracellular, diffusible and circulating glycoprotein, PEDF is secreted by many cell types in addition to RPE, including endothelial cells [32], cardiomyocytes, fibroblasts [30], macrophages [33] and adipocytes [34]. Nevertheless, there is no clear evidence suggesting which kind of cell or tissue specifically expresses PEDF. Current evidence indicates that PEDF binds to laminin receptor (LR) [35], low density lipoprotein related protein 6 (LRP6) [36], Notch receptor [37], phospholipase $\mathrm{A}_{2}\left(\mathrm{PLA}_{2}\right)$ receptor and adipose triglyceride lipase (ATGL) receptor [38]. PEDF has been shown to cause anti-angiogenic, anti-inflammatory and anti-thrombogenic reactions in myeloma cells through the interaction with LR. Accordingly, LR agonist or antagonist may be a target of the reactions in which PEDF is involved. PEDF is an endogenous antagonist of LRP6 and inhibits the canonical Wnt signal pathway [36]. The anti-angiogenic property of PEDF is considered to be dependent upon the induction of Fas ligand (FasL) and Fas receptor (FasR), and result in apoptosis [39]. Besides, the molecular links between PEDF and the PLA $\mathrm{P}_{2}$ receptor may facilitate cardiomyocyte apoptosis via the Fas apoptotic pathway. The combination of interactions with different receptors may drive different responses, which may be the pathophysiological basis of the abovementioned PEDF properties (Fig. 1).

In addition to certain organs, tissues and cell types, human serum also contains PEDF that is closely associated with several diseases, particularly CVD. Yamagishi reported that the concentration of PEDF in human blood is approximately $100-200 \mathrm{nmol} / \mathrm{L}$, and elevated serum PEDF level may be a counter-system in metabolic syndrome (MetS) [40]. There is statistically significant evidence that the level of PEDF decreased after sustained weight loss, indicating that PEDF may act as a buffer against fat mass [41]. One study has shown that patients with MetS had significantly higher level of serum PEDF than non-MetS subjects; similarly, patients with CAD also had significantly higher serum PEDF level than the non-CAD group. Increased PEDF may act as a protective response against vascular damage and subsequent CAD [42], and there is convincing evidence suggesting that the risk of a clinical event independently and gradually elevates with increasing concentrations of PEDF in patients with advanced HF [14]. ACS patients, however, had decreased plasma and intraplatelet level of PEDF [16]. Meanwhile, we have previously shown that ACS patients had notably lower plasma PEDF level relative to the control group and lower PEDF level was further related to adverse cardiac outcomes after ACS [19], and 


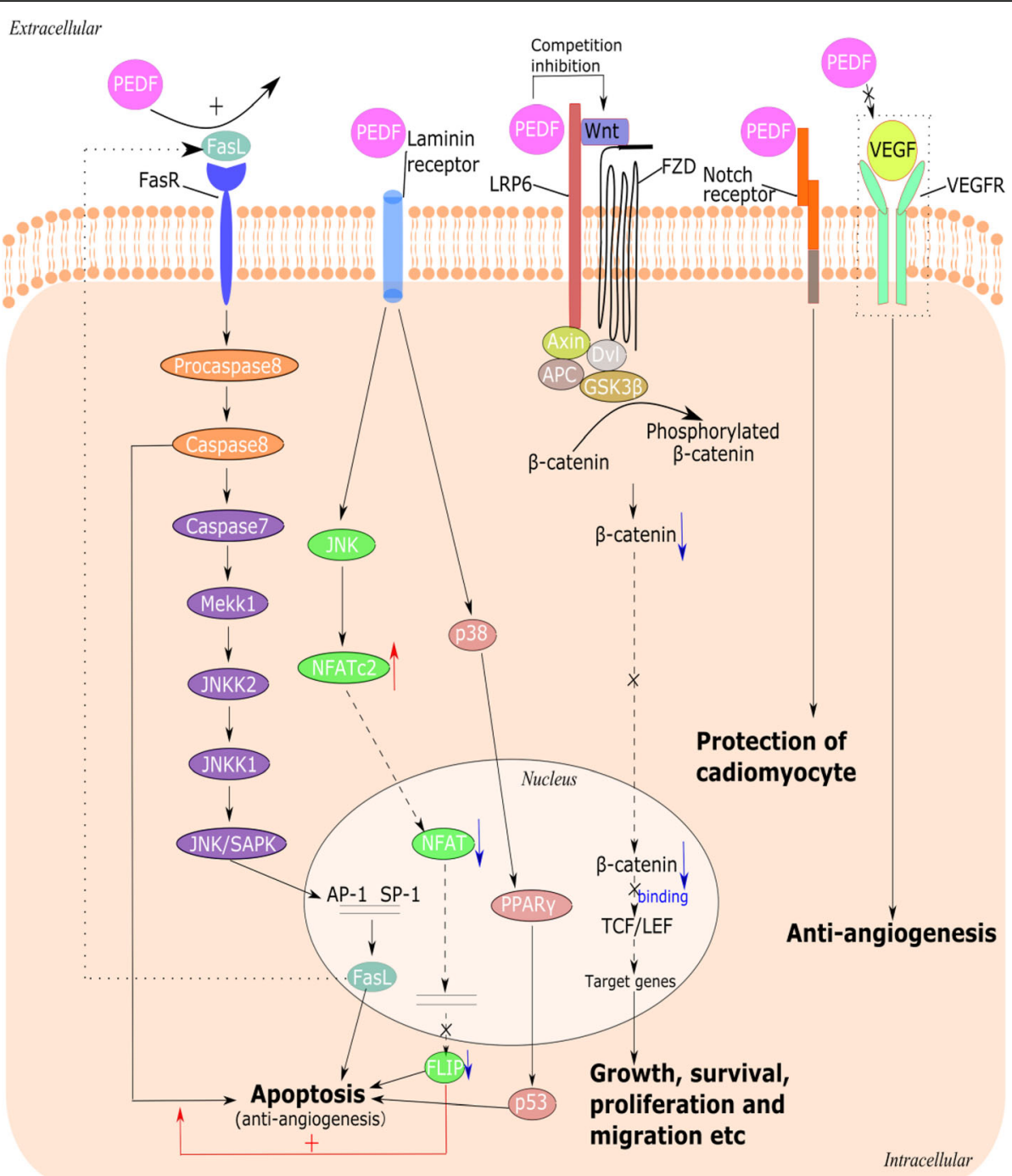

Fig. 1 Several common PEDF receptors and downstream pathways in cell. PEDF can upregulate the pro-apoptotic FasL, promoting the binding of Fas L to FasR and activation of caspase 8 that induces the cell death cascade under certain conditions. PEDF is a ligand of LR and PEDF-LR complex triggers JNKs. Activated JNKs with higher binding affinity to NFATc2 lead to reduced NFAT in the nucleus, downregulating the antiapoptotic factor FLIP. Besides, PEDF activates p38 through LR and subsequently result in activation of PPAR- $\gamma$. As a result, PEDF causes apoptosis, suggesting its anti-angiogenesis. PEDF is an endogenous antagonist of LRP6, the co-receptor of Wnt/ $\beta$-catenin pathway. So PEDF can block the pathway, attenuate $\beta$-catenin nuclear translocation and inhibit the activity of transcription factor TCF/LEF, suggesting a novel mechanism for its protective effects against diabetic retinopathy and endothelial damage. Other common receptors for PEDF are Notch receptor and VEGFR. The binding of PEDF to Notch receptor plays a key role in the protection of cariomyocyte. PEDF inhibits VEGF-driven angiogenesis through the regulated intracellular proteolysis of VEGFR. PEDF, pigment epithelium-derived factor; FasL, Fas ligand; FasR, Fas receptor; LR, laminin receptor; JNK, JUN N-terminal kinase; NFATc2, nuclear factor of activated T-cells, cytoplasmic 2; NFAT, nuclear factor of activated T-cells; FLIP, FLICE-like inhibitory protein; PPAR- $\gamma$, peroxisome proliferator-activated receptor $\gamma$; LRP6, low density lipoprotein related protein 6; TCF, T cell-specific transcription factor; LEF, lymphoid enhancer-binding factor; VEGFR, vascular endothelial growth factor receptor; VEGF, vascular endothelial growth factor

that PEDF level remarkably decreased in CAD patients compared to the controls [20]. Therefore, it is not yet clear whether high or low PEDF serum level accelerates the development of these diseases. Perhaps the association between PEDF and certain diseases is dependent on different pathogenic factors, pathogenesis, receptors, and even individual variation.
The anti-atherosclerosis application of PEDF is debatable. At present, PEDF is believed to be the most potent inhibitor of angiogenesis. It exerts an anti-angiogenesis effect by causing apoptosis of endothelial cells and by disrupting the balance between pro- and anti-angiogenic factors [10]. Thus, it is conceivable that the local downregulation of PEDF in ischemic lesions of the heart could 
promote angiogenesis and neovascularization, contributing to increased perfusion of the injured myocardium [10]. In turn, local excess of PEDF in ischemic lesions might suppress inflammation, oxidative stress, and angiogenesis, and further balance the destabilization and rupture of plaques, inhibiting subsequent thrombus formation.

PEDF was originally recognized for its neurotrophic effects [43, 44]. With in-depth studies, mounting evidence has shown that PEDF can exert anti-angiogenesis, anti-inflammation, anti-oxidization, anti-thrombosis, anti-tumor, and vascular protection effects, among others $[5,10,25,45,46]$. These properties have increased the importance of PEDF in the area of cardiovascular medicine. Endothelial dysfunction, inflammation, oxidization and angiogenesis are vital events in the development and progression of atherosclerosis; therefore, PEDF has promising therapeutic potential for the treatment of atherosclerosis [10].

\section{PEDF and atherosclerosis}

The exposure of vascular cells to CVD risk factors, such as lipids, chronic inflammation, hypertension, diabetes, and stress, is important in the development of atherosclerosis [3]. As a result, these pathogenic factors drive endothelial dysfunction. Vascular permeability is increased, driving lipid infiltration and monocyte accumulation and adhesion. Cholesterol accumulation in the vessel wall, in particular low-density lipoprotein (LDL), has a central role in atherogenesis [47]. LDLs that deposit in the intima can be oxidized or be acted upon by enzymes [48]. These modified LDLs, in turn, can stimulate pro-inflammatory factors, including monocyte chemotactic factors, and enhance inflammation $[47,49]$. Once monocytes transmigrate and reach the subendothelium, they can differentiate into macrophages, engulf modified lipids and convert into foam cells [50]. Meanwhile, VSMCs migrate to the intima where they produce ECM and induce the formation of fibrous caps [51]. The progression of atheroma, loss of VSMCs, apoptosis of foam cells and the release of active metalloproteases can thin the fibrous cap, increasing the susceptibility of plaques to rupture. Ruptured plaques induce severe stenosis or thrombosis in arteries, which leads to regional ischemic damage, such as acute myocardial infarction (AMI) and even death [52]. From a clinical perspective, PEDF may be a factor directly associated with atherosclerosis, and circulating level of PEDF might act as a biochemical marker of atherosclerosis $[18,53]$. From a physiological view, PEDF can play a critical role in atherosclerosis processes based on its anti-inflammatory, anti-oxidant, anti-angiogenic and anti-thrombogenic properties. The following will discuss the underlying anti-atherosclerosis mechanisms of PEDF (Fig. 2).

\section{Endothelial dysfunction}

ECs are essential for maintaining the physiological functions of the cardiovascular system. Endothelial injury or dysfunction has been proposed to be the first step in the initiation of atherosclerosis [54-56]. The presence of severe endothelial dysfunction in CAD patients has been revealed to be a predictor of cardiac death, myocardial infarction (MI) and revascularization [57]. Additionally, endothelial dysfunction is a predictor of adverse outcome in patients after ACS [58-60]. Impaired ECs have been shown to stimulate adhesion molecule expression, release chemotactic factors, increase membrane permeability and enhance the infiltration of LDL into the arterial intima. Furthermore, the subsequent oxidation of LDL exerts cytotoxic effects directly on ECs and promotes the expression of pro-inflammatory cytokines and ROS, which can induce further endothelial dysfunction [61]. Ox-LDL is postulated to be a primary stimulus for monocyte-endothelial interactions. In short, ox-LDL is crucial in endothelial dysfunction and endothelial dysfunction could lead to decreased expression of anti-inflammatory mediators, plaque destabilization [62] and reduced anti-thrombotic tendencies, thereby allowing thrombus formation [63].

PEDF is a multifunctional protein with anti-inflammatory, anti-oxidant, antithrombotic and vascular protective properties. ECs can secret PEDF, and this secretion is critical to suppress the proliferation and migration of VSMCs after balloon injury [32]. There is evidence indicating that PEDF impedes cytokine-, growth factor- and advanced glycation end product (AGE)-induced EC damage [5, 64]. Yamagishi $S$ and colleagues have demonstrated that PEDF could inhibit Ang-II-induced EC activation by suppressing NADPHoxidase-mediated ROS generation, and that PEDF may play a protective role in the development and progression of atherosclerosis [65]. Meanwhile, PEDF could block tumor necrosis factor (TNF)-induced EC activation through its anti-oxidative properties [17]. In agreement with these findings, we found that an apolipoprotein A-I mimetic peptide, D-4F, effectively reduced ox-LDL-induced endothelial injury by upregulating PEDF [23], suggesting that PEDF may protect ECs against damage. Similarly, our latest data shows that PEDF may mitigate endothelial injury by suppressing the $\mathrm{Wnt} / \beta$-catenin pathway [24]. In addition to the direct effects of PEDF on ECs, this compound could play an important role in protecting ECs via its diverse properties, such as its anti-inflammatory and anti-oxidant capabilities. As mentioned above, inflammation and oxidative stress can impact endothelial dysfunction and elicit EC damage. Conversely, endothelial injury or dysfunction upregulates the expression of inflammatory factors and promotes the deposition and oxidization of LDL in the intima. Hence, PEDF, with anti-inflammation and anti-oxidation properties, could limit the interaction 


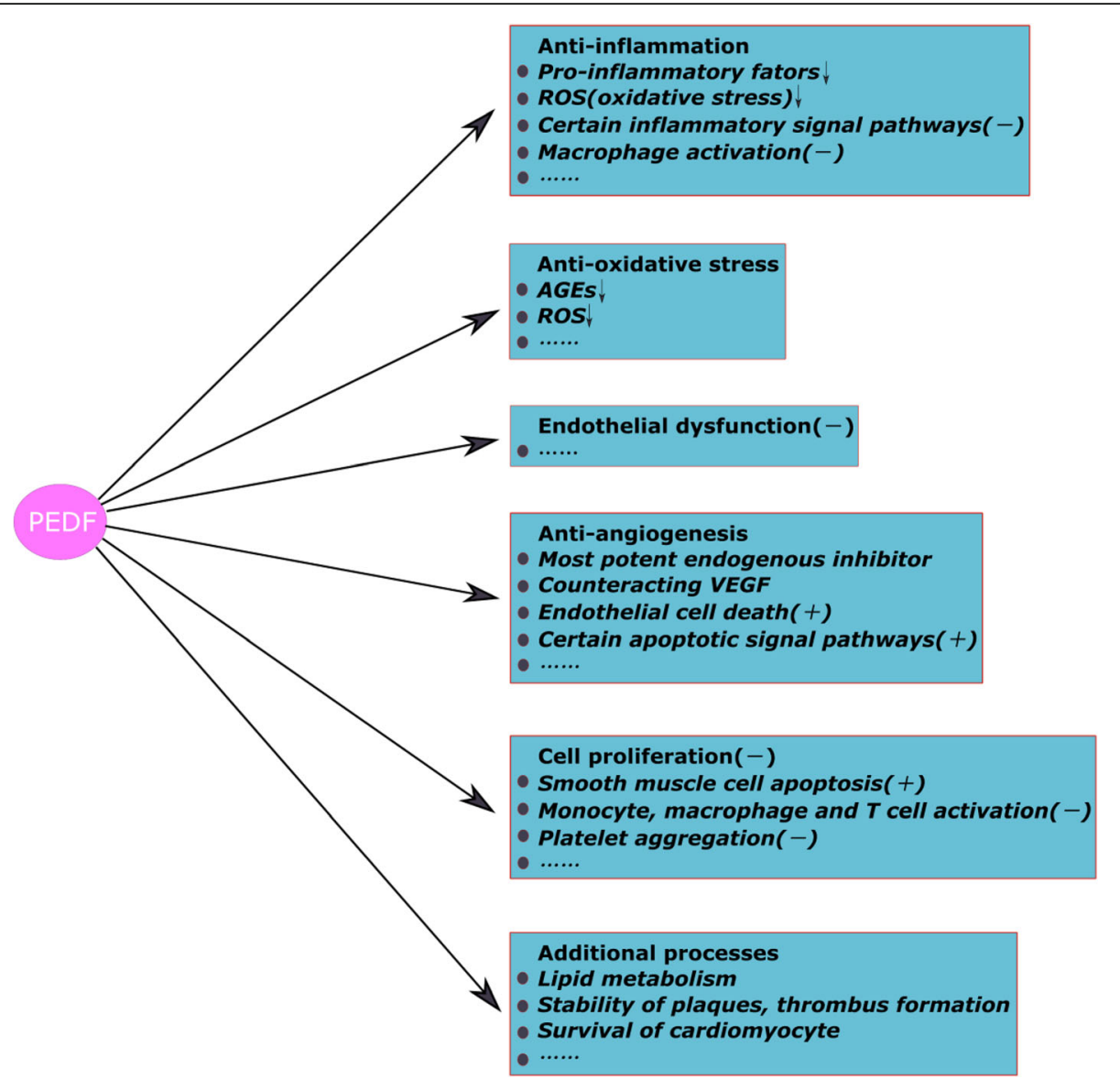

Fig. 2 The putative effects of PEDF on atherosclerosis progression. From a physiological view, PEDF can alleviate the development of atherosclerosis based on its anti-inflammatory, anti-oxidant, anti-angiogenic and anti-thrombogenic properties. The underlying mechanisms of PEDF are listed that form a concerted set of activities to protect health against atherosclerosis. PEDF, pigment epithelium-derived factor

between inflammation, oxidative stress and endothelial dysfunction.

\section{Inflammation}

Atherosclerosis is a complex chronic disease which develops in the arterial wall, and is driven by various risk factors that lead to excessive inflammatory reactions [66]. The inflammatory response is recognized to be pivotal throughout all the steps of atherosclerosis, such as endothelial dysfunction, the formation of fatty streaks, and unstable plaque rupture $[67,68]$. Endothelial dysfunction and lipoprotein accumulation in the intima have been reported to be the earliest events in atherosclerosis with which inflammation is related. Proinflammatory factors can directly injury ECs and elicit endothelial dysfunction. In turn, damaged ECs promote membrane permeability and the infiltration of LDL into the arterial intima. Subsequently, LDL is oxidized or modified by AGEs or inflammatory cytokines. Ox-LDL and modified LDL can enhance monocyte-endothelium adhesion, VSMC migration and increased expression of pro-inflammatory cytokines. An imbalance between anti-inflammatory mechanisms and pro-inflammatory factors will result in atherosclerotic progression. Therefore, inflammation is a key feature of the atherosclerotic process [69].

PEDF is an endogenous anti-inflammatory factor, which may have a protective role in atherosclerosis by inhibiting the proliferative inflammatory response to damage [70]. Recent research has found that PEDF could inhibit inflammation in vivo by suppressing the Ang II-induced increased cellular ROS concentration via regulation of the nuclear factor- $\mathrm{kB}(\mathrm{NF}-\mathrm{kB})$ signal pathway [65]. PEDF could inhibit the macrophage activation elicited by lipopolysaccharides and induce macrophage apoptosis, which demonstrates the potential ability of PEDF to attenuate macrophage-implicated inflammatory activities in diabetic retinopathy [71, 72]. Additionally, PEDF was reported to inhibit the expression of pro-inflammatory factors, including IL-6 [17], vascular endothelial growth factor (VEGF), TNF- $\alpha$ and intercellular adhesion molecule-1 (ICAM-1) [70]. One study 
concluded that the pro-inflammatory effects of heavily oxidized glycated LDL (HOG-LDL) on retinal pericytes were significantly mitigated by PEDF [73]. In addition, the $\mathrm{Wnt} / \beta$-catenin pathway is closely related to inflammation, primarily by a variety of important inflammatory factors [74-76]. Besides, there is evidence suggesting that PEDF may reduce inflammation and oxidative stress by inhibition of the Wnt pathway in unilateral ureteral obstruction kidneys [77]. Similar to these results, our team has demonstrated that ox-LDL-induced human umbilical vein endothelial cell (HUVEC) injury and activation of the Wnt $/ \beta$-catenin pathway were able to be inhibited by PEDF [24]. This effect was, perhaps, partially due to the inhibition of inflammation. Nevertheless, further work is needed to fully elucidate the impacts of PEDF.

\section{Oxidative stress}

Over time, the accumulated evidence from mechanistic studies has indicated the significant role oxidation plays in atherosclerosis pathogenesis. These findings show that oxidative stress can induce the oxidization or modification of lipoproteins, injure vascular ECs, promote the activation of monocytes, macrophages, $\mathrm{T}$ cells and platelets, cause vascular inflammation, and increase the proliferation of VSMCs [78, 79]. Evidence has suggested that induction of ox-LDL, the first event in atherosclerosis, activates intracellular oxidative stress [80, 81]. Oxidative stress, consequently, is believed to play a major role in atherosclerosis.

It has been established that PEDF has anti-oxidative properties, and recent advances have been made to identify the detailed inhibitory effects of PEDF on oxidative stress. Previous studies have indicated that PEDF could suppress occlusive thrombus formation by inhibiting platelet activation and aggregation through its anti-oxidative effect [16]. PEDF was shown to suppress NADPH oxidase activity, which is a molecular target for the anti-oxidative properties of PEDF [10]. It is known that AGEs increase oxidative stress generation, and that PEDF alleviates the effects of AGEs [82, 83]. In addition, Zhang SX and coworkers demonstrated that PEDF effectively alleviated HOG-LDLinduced ROS generation via the upregulation of superoxide dismutase 1 (SOD1) [73]. Our group has also studied PEDF anti-oxidation. Initially, we revealed that ox-LDL led to the downregulation of PEDF in HUVECs, which may have been triggered by the ox-LDL-induced promotion of ROS [22]. Further work by our group has shown that D-4F could mitigate the oxidative stress and endothelial injury by upregulating PEDF, and that PEDF attenuates endothelial injury by blocking the $\mathrm{Wnt} / \beta$-catenin pathway, subsequently ameliorating oxidative stress [24]. These results reveal that PEDF may protect ECs from cytotoxicity and injury via reducing oxidative stress, which may involve certain signal pathways. However, the exact mechanism of oxidative stress is controversial and further research is necessary. Currently, our team is making great efforts in understanding the association between PEDF and oxidative stress by exploring the effect of PEDF on foam cells.

\section{Angiogenesis}

Angiogenesis is characterized by the growth of new blood vessels from preexisting vessels [84] and is a pathological hallmark of chronic vascular disease, such as atherosclerosis and cancer. Similar to endothelial injury, angiogenesis is known to be essential for atherosclerotic plaque development and instability and is a feature of unstable plaques $[85,86]$. Plaque rupture or bleeding is a crucial cause of severe acute cardiovascular events and other complications induced by atherosclerosis, and plaque stability is closely related to the density of neovessels in the lesion $[9,87]$. This has been corroborated by a study from Dunmore BJ et al., which has shown that VEGF, a promoter of angiogenesis, is positively correlated with the destabilization of carotid artery plaque [88]. Moreover, it has been shown that an increasing severity in atherosclerosis corresponded to an increase in the incidence of neovascularization from 31 to $100 \%$, and the instability of new vascular structures, along with the deficiencies in the basement membrane and pericytes, gave rise to plaque instability [89]. Additionally, research has shown that recombinant endostatin is able to inhibit the growth of neovascularization, reduce the area of atherosclerotic plaque and ameliorate the development of new plaques [90]. Neovascularization can disappear with plaque regression induced by a lowering of cholesterol in animals [85, 91]. Notably, angiogenesis is critical in advanced atherosclerosis.

In contrast to VEGF, PEDF is an endogenous inhibitor of pathological angiogenesis, which potently and specifically suppresses pathogenic neovessel growth without injuring mature and preexisting vessels $[92,93]$. There has been much speculation regarding the antiangiogenesis capabilities of PEDF [94]. Initially, Dawson found that PEDF was a more potent angiogenesis inhibitor than angiostatin, a well-studied angiogenesis inhibitor [25]. PEDF is believed to be a far more potent anti-angiogenesis compound than any other known endogenous factors [95]. Notably, PEDF is able to counteract the effects of VEGF. Many studies, which include both in vitro and in vivo experiments, have revealed that PEDF may suppress angiogenesis by exerting a concentration-dependent effect upon VEGF [96]. Mejias $\mathrm{M}$ and associates have found that PEDF upregulation might reflect a compensatory mechanism aimed at alleviating pathological VEGF-induced angiogenesis [93], which is in agreement with other studies [97-99]. In other words, angiogenesis depends on a balance between 
PEDF and VEGF. Several groups contend that the mechanism of PEDF-inhibited new vessel growth might be involved in endothelial cell death through the activation of different pathways, including the Fas/FasL death pathway [100], the JUN N-terminal kinase (JNK) pathway [101] and FLICE-like inhibitory protein (FLIP) [102]. However, further studies are required to fully elucidate the anti-angiogenic mechanisms of PEDF. The general anti-angiogenic property of PEDF has made it a promising therapeutic target for mitigating the progression of angiogenic diseases such as CVD [10].

\section{Cell proliferation}

Previous studies have suggested that the atherosclerotic plaque develops due to the proliferation of endothelial cells, smooth muscle cells, monocytes, macrophages and inflammatory cells [103]. Endothelial cells activation and the subsequently induced inflammatory reaction are critical in the development of atherosclerosis. One study has reported that the smooth muscle cells in the intima can easily proliferate and synthesize ECM and cytokines, thereby promoting atherosclerosis [104]. Increased proliferation of macrophages in the intima can accelerate the formation of early atherosclerotic plaques [105]. The presence of coronary restenosis confirms the clonal proliferation of vascular wall myointimal cells after angioplasty or stent implantation [106]. Additionally, enhanced cell growth, particularly of inflammatory cells, was found to be related to oxidative stress and inflammation in atherosclerotic lesions.

Accumulating evidence supports the idea that PEDF inhibits the proliferation of several types of cells and triggers cell apoptosis. Yamagishi $\mathrm{S}$ and colleagues have indicated that PEDF inhibits angiotensin II-induced smooth muscle cell proliferation due to its anti-oxidative properties [107]. In addition to affecting proliferation, the results of in vitro experiments have shown that PEDF could suppress smooth muscle cell migration, monocyte, macrophage and $\mathrm{T}$ cell activation, and platelet aggregation [5, 64]. Moreover, PEDF was found to promote cell apoptosis. Volpert OV found that PEDF increased FasL expression and subsequently induced apoptosis via caspase-8 [100]. PEDF directly or indirectly induces tumor cell apoptosis [95], such as melanoma [108] and glioma cell [109]. However, it has recently been found that PEDF could upregulate FasL expression and facilitate ECs death $[100,110]$, which is not consistent with our finding that PEDF might reduce endothelial injury [24]. Regarding this issue, Tombran-Tink J and Barnstable CJ have stated that the involvement of PEDF in events that can give rise to both cell survival and cell death lies in the PEDF-activated signaling cascades, suggesting a potential dual activity of PEDF [43]. The mechanisms pertaining to this dual property need to be further discussed.

\section{Additional processes in atherosclerosis}

There are many theories regarding the pathogenesis of atherosclerosis. In addition to those mentioned above, theories relating to the mechanisms of atherosclerosis, including lipid accumulation and infiltration, VSMC mutation, thrombosis and monocyte-macrophage interaction are under investigation. These relevant mechanistic theories require further research. Specifically, PEDF is thought to be correlated with these processes.

Lipids undoubtedly play an essential role in atherosclerosis. PEDF has been identified as a potential regulator of lipid metabolism [111], and loss of PEDF resulted in the accumulation of lipids in ethanol-induced hepatic steatosis [112]. Notari L proposed that ATGL may be a receptor for PEDF [38]. PEDF was found to reduce hepatocyte triglyceride content through its interaction with ATGL in vitro [113]. Furthermore, there are relevant clinical data indicating that serum PEDF level may be related to MeS and diabetes $[40,99,114]$. In turn, lipids are able to regulate the expression of PEDF. Yin $\mathrm{L}$ and coworkers demonstrated that ox-LDL could upregulate the VEGF: PEDF ratio in human retinal pigment epithelial cells [115]. Our group has revealed that ox-LDL downregulates PEDF by increasing ox-LDL-induced intracellular ROS [22].

Advanced atherosclerosis is characterized by plaque rupture and thrombosis. The unstable plaque with chronic inflammation is a precursor for adverse cardiac outcomes. Wen $\mathrm{H}$ and colleagues have revealed that PEDF improves the stability of atherosclerotic plaques by ameliorating the macrophage inflammation response, which is closely associated with peroxisome proliferator-activated receptor $\gamma$ (PPAR- $\gamma$ ) and downstream mitogen-activated protein kinase (MAPK) [116]. There is evidence suggesting that PEDF can inhibit occlusive thrombus formation by blocking platelet activation and aggregation [16], and it may prevent atherothrombosis in patients with diabetes mellitus by inhibiting the CD40-CD40L axis [117, 118]. PEDF may instigate macrophage apoptosis and necrosis through the signaling of PPAR $-\gamma$, reducing the accumulation and infiltration of macrophages in the lesion area, which increases plaque stability [72].

Interestingly, PEDF has been found to be involved in the survival of cardiomyocytes. Research shown that a reduction in both adenosine triphosphate (ATP) production and expenditure, controlled by PEDF, can reduce cardiomyocyte energy failure and increase its energy reserves, thereby prolonging cardiomyocyte activity during oxygen-glucose deprivation which is associated with an AMP-activated protein kinase (AMPK)-dependent degradation pathway [119]. These data demonstrate the 
protective effect of PEDF against hypoxia in cardiomyocytes and show that PEDF may exert this function in atherosclerosis-driven ischemic heart disease. Furthermore, Gao X and assistants revealed that PEDF and its functional PEDF-derived peptide 44mer may protect cardiomyocytes against apoptosis and necroptosis under hypoxic conditions via an anti-oxidative effect [120].

\section{Conclusions}

PEDF is a multifaceted compound that can impact atherosclerosis through impacting various pathological responses, including endothelial dysfunction, inflammation, oxidative stress, angiogenesis, cell proliferation and other processes. Current research has also reported on the effective potential of this versatile protein against other diseases, such as eye disorders and cancer. Our group has revealed an association of PEDF with ACS and CAD, and we have explored the role of PEDF in ox-LDL-induced endothelial injury. However, considerably more work is required to fully understand the beneficial effects of PEDF on CVD, particularly on atherosclerosis. First, it is necessary to elucidate how PEDF, either directly or indirectly, impacts each component of atherosclerosis. Second, further research is required to discover the essential domain of PEDF to which the particular effects of the polypeptide are attributed. Third, receptors for PEDF are of great interest in atherosclerotic progression and cell biology. Thus, more extensive studies are needed to clarify the mechanisms of the biochemical pathways that PEDF impacts and the PEDF receptor signaling cascades. In conclusion, due to its diverse effects, PEDF is becoming a promising novel therapeutic agent in the fight against atherosclerosis, without compilations of resistance and toxicity. Although there are many in vitro and in vivo studies indicating the benefits of PEDF, the full potential of this compound requires further clinical exploration.

\section{Abbreviations}

ACS: Acute coronary syndrome; AGE: Advanced glycation end product; AMI: Acute myocardial infarction; AMPK: AMP-activated protein kinase; ATGL: Adipose triglyceride lipase; ATP: Adenosine triphosphate; BNP: Brain natriuretic peptide; CAD: Coronary artery disease; CVD: Cardiovascular disease; EC: Endothelial cell; ECM: Extracellular matrix; FasL: Fas ligand; FasR: Fas receptor; FLIP: FLICE-like inhibitory protein; HF: Heart failure; HOG-LDL: Heavily oxidized glycated LDL; HUVEC: Human umbilical vein endothelial cell; ICAM: Intercellular adhesion molecule; JNK: JUN N-terminal kinase; LDL: Low density lipoprotein; LR: Laminin receptor; LRP: Low density lipoprotein related protein; MAPK: Mitogen-activated protein kinase; MetS: Metabolic syndrome; MI: Myocardial infarction; NF-kB: Nuclear factor-kB; Ox-LDL: oxidized-low density lipoprotein; PEDF: Pigment epithelium-derived factor; PLA: Phospholipase $A_{2}$ PPAR-Y: Peroxisome proliferator-activated receptor $\gamma$; ROS: Reactive oxygen species; RPE: Retinal pigment epithelium; SERPIN: Serine protease inhibitor; SNP: Single nucleotide polymorphism; SOD: Superoxide dismutase; TNF: Tumor necrosis factor; VEGF: Vascular endothelial growth factor; VSMC: Vascular smooth muscle cell

\section{Funding}

This work was supported by the National Natural Science Foundations of China (81470504) and Logistics Scientific Research Project of Chinese PLA (15BJZ37).

\section{Authors' contributions}

SM and SW proposed the idea and drafted the manuscript, ML and YZ were involved in the accumulation of the relevant references, and PZ revised and corrected the final version. All authors read and approved the final manuscript.

Ethics approval and consent to participate

Not applicable.

Consent for publication

Not applicable.

Competing interests

The authors declare that they have no competing interests.

\section{Publisher's Note}

Springer Nature remains neutral with regard to jurisdictional claims in published maps and institutional affiliations.

\section{Author details}

${ }^{1}$ Department of Geriatric Cardiology, Chinese PLA General Hospital, Beijing 100853, China. 'Department of Cadre Clinic, Chinese PLA General Hospital, Beijing 100853, China.

Received: 2 April 2018 Accepted: 3 October 2018

Published online: 17 October 2018

\section{References}

1. Global Burden of Disease Study C. Global, regional, and national incidence, prevalence, and years lived with disability for 301 acute and chronic diseases and injuries in 188 countries, 1990-2013: a systematic analysis for the global burden of disease study 2013. Lancet. 2015;386:743-800.

2. Roth GA, Forouzanfar MH, Moran AE, Barber R, Nguyen G, Feigin VL, Naghavi M, Mensah GA, Murray CJ. Demographic and epidemiologic drivers of global cardiovascular mortality. N Engl J Med. 2015;372:1333-41.

3. Badimon L, Vilahur G. Thrombosis formation on atherosclerotic lesions and plaque rupture. J Intern Med. 2014;276:618-32.

4. Go AS, Mozaffarian D, Roger VL, Benjamin EJ, Berry JD, Blaha MJ, Dai S, Ford ES, Fox CS, Franco S, et al. Heart disease and stroke statistics--2014 update: a report from the American Heart Association. Circulation. 2014;129:e28-e292.

5. Yamagishi SI, Matsui T. Anti-atherothrombogenic properties of PEDF. Curr Mol Med. 2010;10:284-91.

6. Tsaousi A, Mill C, George SJ. The Wnt pathways in vascular disease: lessons from vascular development. Curr Opin Lipidol. 2011:22:350-7.

7. Ding L, Biswas S, Morton RE, Smith JD, Hay N, Byzova TV, Febbraio M, Podrez EA. Akt3 deficiency in macrophages promotes foam cell formation and atherosclerosis in mice. Cell Metab. 2012;15:861-72.

8. Williams HJ, Fisher EA, Greaves DR. Macrophage differentiation and function in atherosclerosis: opportunities for therapeutic intervention? I Innate Immun. 2012:4:498-508.

9. Hellings WE, Peeters W, Moll FL, Piers SR, van Setten J, Van der Spek PJ, de Vries JP, Seldenrijk KA, De Bruin PC, Vink A, et al. Composition of carotid atherosclerotic plaque is associated with cardiovascular outcome: a prognostic study. Circulation. 2010;121:1941-50.

10. Rychli K, Huber K, Wojta J. Pigment epithelium-derived factor (PEDF) as a therapeutic target in cardiovascular disease. Expert Opin Ther Targets. 2009; 13:1295-302.

11. Yamagishi S, Matsui T. Pigment epithelium-derived factor (PEDF) and cardiometabolic disorders. Curr Pharm Des. 2014:20:2377-86.

12. Anastas JN, Moon RT. WNT signalling pathways as therapeutic targets in cancer. Nat Rev Cancer. 2013;13:11-26.

13. Filleur S, Nelius T, de Riese W, Kennedy RC. Characterization of PEDF: a multi-functional serpin family protein. J Cell Biochem. 2009;106:769-75.

14. Rychli K, Niessner A, Hohensinner PJ, Mahdy Ali K, Kaun C, Neuhold S, Zorn $G$, Richter B, Hulsmann M, Berger R, et al. Prognostic value of pigment epithelium-derived factor in patients with advanced heart failure. Chest. 2010;138:656-64.

15. Chen C, Tso AW, Cheung BM, Law LS, Ong KL, Wat NM, Janus ED, Xu A, Lam KS. Plasma concentration of pigment epithelium-derived factor is closely associated with blood pressure and predicts incident hypertension in Chinese: a 10-year prospective study. Clin Endocrinol. 2012;76:506-13. 
16. Takenaka K, Yamagishi S, Matsui T, Nakamura K, Jinnouchi Y, Yoshida Y, Ueda S, Katsuki Y, Katsuda Y, Imaizumi T. Pigment epithelium-derived factor (PEDF) administration inhibits occlusive thrombus formation in rats: a possible participation of reduced intraplatelet PEDF in thrombosis of acute coronary syndromes. Atherosclerosis. 2008;197:25-33.

17. Yamagishi $S$, Inagaki $Y$, Nakamura $K$, Abe $R$, Shimizu $T$, Yoshimura A, Imaizumi T. Pigment epithelium-derived factor inhibits TNF-alphainduced interleukin-6 expression in endothelial cells by suppressing NADPH oxidase-mediated reactive oxygen species generation. J Mol Cell Cardiol. 2004;37:497-506.

18. Tahara N, Yamagishi S, Tahara A, Nitta Y, Kodama N, Mizoguchi M, Mohar D, Ishibashi M, Hayabuchi N, Imaizumi T. Serum level of pigment epitheliumderived factor is a marker of atherosclerosis in humans. Atherosclerosis. 2011;219:311-5.

19. Liu J, Wang S, Shi J, Guo Y, Liu J, Tao T, Zhu P. The association study of plasma levels of pigment epithelium-derived factor with acute coronary syndrome in the chinese han population. Cardiology. 2014;127:31-7.

20. Li M, Wang S, Zhang Y, Ma S, Zhu P. Correlation between pigment epithelium-derived factor (PEDF) level and degree of coronary angiography and severity of coronary artery disease in a Chinese population. Med Sci Monit. 2018;24:1751-8.

21. Ma SY, Guo YY, Wang SX, Shi JX, Liu J, Liu JF, Zhu P. The T allele of

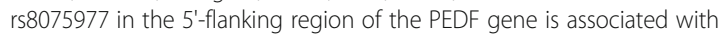
reduced risk of coronary artery disease in elderly Chinese men. Tohoku Exp Med. 2017;241:297-308.

22. Liu J, Yao ST, Zhai L, Feng YL, Song GH, Yu Y, Zhu P, Qin SC. Ox-LDL downregulates expression of pigment epithelium-derived factor in human umbilical vein endothelial cells. Sheng Li Xue Bao. 2014;66:489-95.

23. Liu J, Yao S, Wang S, Jiao P, Song G, Yu Y, Zhu P, Qin S. D-4F, an apolipoprotein A-I mimetic peptide, protects human umbilical vein endothelial cells from oxidized low-density lipoprotein-induced injury by preventing the downregulation of pigment epithelium-derived factor expression. J Cardiovasc Pharmacol. 2014;63:553-61.

24. Ma S, Yao S, Tian H, Jiao P, Yang N, Zhu P, Qin S. Pigment epitheliumderived factor alleviates endothelial injury by inhibiting Wnt/beta-catenin pathway. Lipids Health Dis. 2017;16:31.

25. Dawson DW, Volpert OV, Gillis P, Crawford SE, Xu H, Benedict W, Bouck NP. Pigment epithelium-derived factor: a potent inhibitor of angiogenesis. Science. 1999;285:245-8

26. Sawant S, Aparicio S, Tink AR, Lara N, Barnstable CJ, Tombran-Tink J. Regulation of factors controlling angiogenesis in liver development: a role for PEDF in the formation and maintenance of normal vasculature. Biochem Biophys Res Commun. 2004;325:408-13.

27. Bilak MM, Corse AM, Bilak SR, Lehar M, Tombran-Tink J, Kund RW. Pigment epithelium-derived factor (PEDF) protects motor neurons from chronic glutamatemediated neurodegeneration. J Neuropathol Exp Neurol. 1999:58:719-28.

28. Uehara $\mathrm{H}$, Miyamoto $M$, Kato $K$, Ebihara $Y$, Kaneko $H$, Hashimoto $H$, Murakami Y, Hase R, Takahashi R, Mega S, et al. Expression of pigment epithelium-derived factor decreases liver metastasis and correlates with favorable prognosis for patients with ductal pancreatic adenocarcinoma. Cancer Res. 2004;64:3533-7.

29. Quan GM, Ojaimi J, Li Y, Kartsogiannis V, Zhou H, Choong PF. Localization of pigment epithelium-derived factor in growing mouse bone. Calcif Tissue Int. 2005;76:146-53.

30. Rychli K, Kaun C, Hohensinner PJ, Dorfner AJ, Pfaffenberger S, Niessner A, Bauer M, Dietl W, Podesser BK, Maurer G, et al. The anti-angiogenic factor PEDF is present in the human heart and is regulated by anoxia in cardiac myocytes and fibroblasts. J Cell Mol Med. 2010;14:198-205.

31. Alberdi E, Hyde CC, Becerra SP. Pigment epithelium-derived factor (PEDF) binds to glycosaminoglycans: analysis of the binding site. Biochemistry. 1998;37:10643-52.

32. Nakamura K, Yamagishi S, Matsui T, Yoshida T, Takenaka K, Jinnouchi Y, Yoshida Y, Ueda S, Adachi H, Imaizumi T. Pigment epithelium-derived factor inhibits neointimal hyperplasia after vascular injury by blocking NADPH oxidase-mediated reactive oxygen species generation. Am J Pathol. 2007; 170:2159-70.

33. Baba H, Yonemitsu Y, Nakano T, Onimaru M, Miyazaki M, Ikeda Y, Sumiyoshi S, Ueda Y, Hasegawa M, Yoshino I, et al. Cytoplasmic expression and extracellular deposition of an antiangiogenic factor, pigment epitheliumderived factor, in human atherosclerotic plaques. Arterioscler Thromb Vasc Biol. 2005;25:1938-44.
34. Nakamura K, Yamagishi S, Adachi H, Kurita-Nakamura Y, Matsui T, Inoue H. Serum levels of pigment epithelium-derived factor (PEDF) are positively associated with visceral adiposity in Japanese patients with type 2 diabetes. Diabetes Metab Res Rev. 2009:25:52-6.

35. Bernard A, Gao-Li J, Franco CA, Bouceba T, Huet A, Li Z. Laminin receptor involvement in the anti-angiogenic activity of pigment epithelium-derived factor. J Biol Chem. 2009;284:10480-90.

36. Park K, Lee K, Zhang B, Zhou T, He X, Gao G, Murray AR, Ma JX. Identification of a novel inhibitor of the canonical Wnt pathway. Mol Cell Biol. 2011;31:3038-51.

37. Andreu-Agullo C, Morante-Redolat JM, Delgado AC, Farinas I. Vascular niche factor PEDF modulates notch-dependent stemness in the adult subependymal zone. Nat Neurosci. 2009;12:1514-23.

38. Notari L, Baladron V, Aroca-Aguilar JD, Balko N, Heredia R, Meyer C, Notario PM, Saravanamuthu S, Nueda ML, Sanchez-Sanchez F, et al. Identification of a lipase-linked cell membrane receptor for pigment epithelium-derived factor. J Biol Chem. 2006;281:38022-37.

39. Becerra SP, Notario V. The effects of PEDF on cancer biology: mechanisms of action and therapeutic potential. Nat Rev Cancer. 2013;13:258-71.

40. Yamagishi S, Adachi H, Abe A, Yashiro T, Enomoto M, Furuki K, Hino A, Jinnouchi $Y$, Takenaka $K$, Matsui $T$, et al. Elevated serum levels of pigment epithelium-derived factor in the metabolic syndrome. J Clin Endocrinol Metab. 2006;91:2447-50.

41. Geyer PE, Wewer Albrechtsen NJ, Tyanova S, Grassl N, lepsen EW, Lundgren J, Madsbad S, Holst JJ, Torekov SS, Mann M. Proteomics reveals the effects of sustained weight loss on the human plasma proteome. Mol Syst Biol. 2016;12:901.

42. Wang F, Ma X, Zhou M, Pan X, Ni J, Gao M, Lu Z, Hang J, Bao Y, Jia W. Serum pigment epithelium-derived factor levels are independently correlated with the presence of coronary artery disease. Cardiovasc Diabetol. 2013;12:56

43. Tombran-Tink J, Barnstable CJ. PEDF: a multifaceted neurotrophic factor Nat Rev Neurosci. 2003;4:628-36.

44. Steele FR, Chader GJ, Johnson LV, Tombran-Tink J. Pigment epithelium-derived factor: neurotrophic activity and identification as a member of the serine protease inhibitor gene family. Proc Natl Acad Sci U S A. 1993:90:1526-30.

45. Yamagishi S, Matsui T, Nakamura K, Ueda S, Noda Y, Imaizumi T. Pigment epithelium-derived factor (PEDF): its potential therapeutic implication in diabetic vascular complications. Curr Drug Targets. 2008;9:1025-9.

46. Manalo KB, Choong PF, Dass CR. Pigment epithelium-derived factor as an impending therapeutic agent against vascular epithelial growth factordriven tumor-angiogenesis. Mol Carcinog. 2011;50:67-72.

47. Hedrick CC. Lymphocytes in atherosclerosis. Arterioscler Thromb Vasc Biol. 2015;35:253-7.

48. Badimon L, Vilahur G, Padro T. Lipoproteins, platelets and atherothrombosis. Rev Esp Cardiol. 2009;62:1161-78.

49. Frostegard J. Immunity, atherosclerosis and cardiovascular disease. BMC Med. 2013;11:117.

50. Badimon L, Storey RF, Vilahur G. Update on lipids, inflammation and atherothrombosis. Thromb Haemost. 2011;105(Suppl 1):S34-42.

51. Koga J, Aikawa M. Crosstalk between macrophages and smooth muscle cells in atherosclerotic vascular diseases. Vasc Pharmacol. 2012;57:24-8.

52. Libby P. Mechanisms of acute coronary syndromes and their implications for therapy. N Engl J Med. 2013;368:2004-13.

53. Kajikawa M, Maruhashi T, Iwamoto Y, Iwamoto A, Oda N, Kishimoto S, Matsui S, Aibara Y, Hidaka T, Kihara Y, et al. Circulating level of pigment epithelium-derived factor is associated with vascular function and structure: a cross-sectional study. Int J Cardiol. 2016;225:91-5.

54. Lusis AJ. Atherosclerosis. Nature. 2000;407:233-41.

55. Yamagishi S, Nakamura K, Matsui T, Ueda S, Fukami K, Okuda S. Agents that block advanced glycation end product (AGE)-RAGE (receptor for AGEs)oxidative stress system: a novel therapeutic strategy for diabetic vascular complications. Expert Opin Investig Drugs. 2008;17:983-96.

56. Karra R, Vemullapalli S, Dong C, Herderick EE, Song X, Slosek K, Nevins JR, West M, Goldschmidt-Clermont PJ, Seo D. Molecular evidence for arterial repair in atherosclerosis. Proc Natl Acad Sci U S A. 2005;102:16789-94.

57. Suwaidi JA, Hamasaki S, Higano ST, Nishimura RA, Holmes DR Jr, Lerman A. Long-term follow-up of patients with mild coronary artery disease and endothelial dysfunction. Circulation. 2000;101:948-54.

58. Fichtlscherer S, Breuer S, Zeiher AM. Prognostic value of systemic endothelial dysfunction in patients with acute coronary syndromes: further 
evidence for the existence of the "vulnerable" patient. Circulation. 2004;110: 1926-32.

59. Careri G, Nerla R, Di Monaco A, Russo G, Stazi A, Villano A, Sestito A, Lanza GA, Crea F. Clinical correlates and prognostic value of flow mediated dilation in patients with non-ST segment elevation acute coronary syndromes. Am J Cardiol. 2013;111:51-7.

60. Bissinger A, Grycewicz T, Grabowicz W, Lubinski A. Endothelial function and left ventricular remodeling in diabetic and non-diabetic patients after acute coronary syndrome. Med Sci Monit. 2011;17:CR73-7.

61. Sauer H, Wartenberg M. Circulating isoprostanes: gate keepers in the route from oxidative stress to vascular dysfunction. Circ Res. 2008;103:907-9.

62. Koenig W, Khuseyinova N. Biomarkers of atherosclerotic plaque instability and rupture. Arterioscler Thromb Vasc Biol. 2007;27:15-26.

63. Tousoulis D, Charakida M, Stefanadis C. Endothelial function and inflammation in coronary artery disease. Heart. 2006;92:441-4.

64. Maeda S, Matsui T, Takeuchi M, Yoshida Y, Yamakawa R, Fukami K, Yamagishi S. Pigment epithelium-derived factor (PEDF) inhibits proximal tubular cell injury in early diabetic nephropathy by suppressing advanced glycation end products (AGEs)-receptor (RAGE) axis. Pharmacol Res. 2011;63:241-8.

65. Yamagishi S, Nakamura K, Ueda S, Kato S, Imaizumi T. Pigment epitheliumderived factor (PEDF) blocks angiotensin II signaling in endothelial cells via suppression of NADPH oxidase: a novel anti-oxidative mechanism of PEDF. Cell Tissue Res. 2005;320:437-45.

66. Li JJ. Inflammation in coronary artery diseases. Chin Med J. 2011;124:3568-75.

67. Berliner JA, Navab M, Fogelman AM, Frank JS, Demer LL, Edwards PA, Watson AD, Lusis AJ. Atherosclerosis: basic mechanisms. Oxidation, inflammation, and genetics. Circulation. 1995;91:2488-96.

68. Libby P. Inflammation and cardiovascular disease mechanisms. Am J Clin Nutr. 2006:83:456S-60S.

69. Abderrazak A, Couchie D, Mahmood DF, Elhage R, Vindis C, Laffargue M, Mateo V, Buchele B, Ayala MR, El Gaafary M, et al. Anti-inflammatory and antiatherogenic effects of the NLRP3 inflammasome inhibitor arglabin in ApoE2.Ki mice fed a high-fat diet. Circulation. 2015;131:1061-70.

70. Zhang SX, Wang JJ, Gao G, Shao C, Mott R, Ma JX. Pigment epitheliumderived factor (PEDF) is an endogenous antiinflammatory factor. FASEB $\mathrm{J}$. 2006;20:323-5.

71. Zamiri P, Masli S, Streilein JW, Taylor AW. Pigment epithelial growth factor suppresses inflammation by modulating macrophage activation. Invest Ophthalmol Vis Sci. 2006:47:3912-8.

72. Ho TC, Yang YC, Chen SL, Kuo PC, Sytwu HK, Cheng HC, Tsao YP. Pigment epithelium-derived factor induces THP-1 macrophage apoptosis and necrosis by the induction of the peroxisome proliferator-activated receptor gamma. Mol Immunol. 2008:45:898-909.

73. Zhang SX, Wang JJ, Dashti A, Wilson K, Zou MH, Szweda L, Ma JX, Lyons TJ. Pigment epithelium-derived factor mitigates inflammation and oxidative stress in retinal pericytes exposed to oxidized low-density lipoprotein. J Mol Endocrinol. 2008:41:135-43.

74. Silva-Garcia O, Valdez-Alarcon JJ, Baizabal-Aguirre VM. The Wnt/beta-catenin signaling pathway controls the inflammatory response in infections caused by pathogenic bacteria. Mediat Inflamm. 2014;2014:310183.

75. Halleskog C, Mulder J, Dahlstrom J, Mackie K, Hortobagyi T, Tanila H, Kumar Puli L, Farber K, Harkany T, Schulte G. WNT signaling in activated microglia is proinflammatory. Glia. 2011;59:119-31.

76. Zhou T, Hu Y, Chen Y, Zhou KK, Zhang B, Gao G, Ma JX. The pathogenic role of the canonical Wnt pathway in age-related macular degeneration. Invest Ophthalmol Vis Sci. 2010;51:4371-9.

77. He X, Cheng R, Park K, Benyajati S, Moiseyev G, Sun C, Olson LE, Yang Y, Eby BK, Lau K, et al. Pigment epithelium-derived factor, a noninhibitory serine protease inhibitor, is renoprotective by inhibiting the Wnt pathway. Kidney Int. 2017;91:642-57.

78. Yamagishi S, Nakamura K, Matsui T. Role of oxidative stress in the development of vascular injury and its therapeutic intervention by nifedipine. Curr Med Chem. 2008;15:172-7.

79. Piddock $L$. Mechanisms of resistance to fluoroquinolones: state-of-the-art 1992-1994. Drugs. 1995;49(Suppl 2):29-35.

80. Mitra S, Goyal T, Mehta JL. Oxidized LDL, LOX-1 and atherosclerosis. Cardiovasc Drugs Ther. 2011;25:419-29.

81. Arjuman A, Chandra NC. Effect of IL-10 on LOX-1 expression, signalling and functional activity: an atheroprotective response. Diab Vasc Dis Res. 2013;10:442-51.
82. Yamagishi S, Matsui T, Nakamura K, Yoshida T, Takeuchi M, Inoue H, Yoshida $Y$, Imaizumi T. Pigment-epithelium-derived factor suppresses expression of receptor for advanced glycation end products in the eye of diabetic rats. Ophthalmic Res. 2007;39:92-7.

83. Yamagishi S, Imaizumi T. Diabetic vascular complications: pathophysiology, biochemical basis and potential therapeutic strategy. Curr Pharm Des. 2005; 11:2279-99.

84. Carmeliet P, Jain RK. Molecular mechanisms and clinical applications of angiogenesis. Nature. 2011;473:298-307.

85. Falk E. Pathogenesis of atherosclerosis. J Am Coll Cardiol. 2006;47:C7-12.

86. Naghavi M, Libby P, Falk E, Casscells SW, Litovsky S, Rumberger J, Badimon $\mathrm{JJ}$, Stefanadis C, Moreno P, Pasterkamp G, et al. From vulnerable plaque to vulnerable patient: a call for new definitions and risk assessment strategies: part I. Circulation. 2003;108:1664-72.

87. Derksen WJ, Peeters W, Tersteeg C, de Vries JP, de Kleijn DP, Moll FL, van der Wal AC, Pasterkamp G, Vink A. Age and coumarin-type anticoagulation are associated with the occurrence of intraplaque hemorrhage, while statins are associated less with intraplaque hemorrhage: a large histopathological study in carotid and femoral plaques. Atherosclerosis. 2011;214:139-43.

88. Dunmore BJ, McCarthy MJ, Naylor AR, Brindle NP. Carotid plaque instability and ischemic symptoms are linked to immaturity of microvessels within plaques. J Vasc Surg. 2007:45:155-9.

89. Pedersen SF, Thrysoe SA, Paaske WP, Thim T, Falk E, Ringgaard S, Kim WY CMR assessment of endothelial damage and angiogenesis in porcine coronary arteries using gadofosveset. J Cardiovasc Magn Reson. 2011;13:10.

90. Mao W, Kong J, Dai J, Huang ZQ, Wang DZ, Ni GB, Chen ML. Evaluation of recombinant endostatin in the treatment of atherosclerotic plaques and neovascularization in rabbits. J Zhejiang Univ Sci B. 2010;11:599-607.

91. Sakakura K, Nakano M, Otsuka F, Ladich E, Kolodgie FD, Virmani R. Pathophysiology of atherosclerosis plaque progression. Heart Lung Circ. 2013;22:399-411.

92. Keane MP. Angiogenesis and pulmonary fibrosis: feast or famine? Am J Respir Crit Care Med. 2004;170:207-9.

93. Mejias M, Coch L, Berzigotti A, Garcia-Pras E, Gallego J, Bosch J, Fernandez M. Antiangiogenic and antifibrogenic activity of pigment epithelium-derived factor (PEDF) in bile duct-ligated portal hypertensive rats. Gut. 2015;64:657-66.

94. Matsumoto K, Ishikawa H, Nishimura D, Hamasaki K, Nakao K, Eguchi K. Antiangiogenic property of pigment epithelium-derived factor in hepatocellular carcinoma. Hepatology. 2004;40:252-9.

95. Ek ET, Dass CR, Choong PF. PEDF: a potential molecular therapeutic target with multiple anti-cancer activities. Trends Mol Med. 2006;12:497-502.

96. Becker J, Semler O, Gilissen C, Li Y, Bolz HJ, Giunta C, Bergmann C, Rohrbach $M$, Koerber $F$, Zimmermann $K$, et al. Exome sequencing identifies truncating mutations in human SERPINF1 in autosomal-recessive osteogenesis imperfecta. Am J Hum Genet. 2011;88:362-71.

97. Kawaguchi T, Yamagishi S, Itou M, Okuda K, Sumie S, Kuromatsu R, Sakata M, Abe M, Taniguchi E, Koga H, et al. Pigment epithelium-derived factor inhibits lysosomal degradation of BCl-xL and apoptosis in HepG2 cells. Am J Pathol. 2010;176:168-76.

98. Doll JA, Stellmach VM, Bouck NP, Bergh AR, Lee C, Abramson LP, Cornwell ML, Pins MR, Borensztajn J, Crawford SE. Pigment epithelium-derived factor regulates the vasculature and mass of the prostate and pancreas. Nat Med. 2003;9:774-80.

99. Ogata N, Matsuoka M, Matsuyama K, Shima C, Tajika A, Nishiyama T, Wada $\mathrm{M}$, Jo N, Higuchi A, Minamino K, et al. Plasma concentration of pigment epithelium-derived factor in patients with diabetic retinopathy. J Clin Endocrinol Metab. 2007;92:1176-9.

100. Volpert OV, Zaichuk T, Zhou W, Reiher F, Ferguson TA, Stuart PM, Amin M, Bouck NP. Inducer-stimulated Fas targets activated endothelium for destruction by anti-angiogenic thrombospondin-1 and pigment epitheliumderived factor. Nat Med. 2002;8:349-57.

101. Konson A, Pradeep S, D'Acunto CW, Seger R. Pigment epithelium-derived factor and its phosphomimetic mutant induce JNK-dependent apoptosis and p38-mediated migration arrest. J Biol Chem. 2011;286:3540-51.

102. Biyashev D, Veliceasa D, Kwiatek A, Sutanto MM, Cohen RN, Volpert OV. Natural angiogenesis inhibitor signals through Erk5 activation of peroxisome proliferator-activated receptor gamma (PPARgamma). J Biol Chem. 2010;285: $13517-24$.

103. Ross JS, Stagliano NE, Donovan MJ, Breitbart RE, Ginsburg GS. Atherosclerosis: a cancer of the blood vessels? Am J Clin Pathol. 2001; 116(Suppl):S97-107. 
104. Owens GK, Kumar MS, Wamhoff BR. Molecular regulation of vascular smooth muscle cell differentiation in development and disease. Physiol Rev. 2004:84:767-801

105. Zhu SN, Chen M, Jongstra-Bilen J, Cybulsky MI. GM-CSF regulates intimal cell proliferation in nascent atherosclerotic lesions. J Exp Med. 2009;206: 2141-9.

106. O'Brien ER, Urieli-Shoval S, Garvin MR, Stewart DK, Hinohara T, Simpson JB, Benditt EP, Schwartz SM. Replication in restenotic atherectomy tissue. Atherosclerosis. 2000;152:117-26.

107. Yamagishi S, Matsui T, Nakamura K, Imaizumi T. Pigment epithelium-derived factor (PEDF) inhibits angiotensin Il-induced smooth muscle cell proliferation through its anti-oxidative properties. Protein Pept Lett. 2007;14: 615-7.

108. Abe R, Fujita Y, Yamagishi S, Shimizu H. Pigment epithelium-derived factor prevents melanoma growth via angiogenesis inhibition. Curr Pharm Des. 2008;14:3802-9.

109. Zhang T, Guan M, Xu C, Chen Y, Lu Y. Pigment epithelium-derived factor inhibits glioma cell growth in vitro and in vivo. Life Sci. 2007;81:1256-63.

110. Broadhead ML, Dass CR, Choong PF. Cancer cell apoptotic pathways mediated by PEDF: prospects for therapy. Trends Mol Med. 2009;15:461-7.

111. Borg ML, Andrews ZB, Duh EJ, Zechner R, Meikle PJ, Watt MJ. Pigment epithelium-derived factor regulates lipid metabolism via adipose triglyceride lipase. Diabetes. 2011;60:1458-66.

112. Chung C, Shugrue C, Nagar A, Doll JA, Cornwell M, Gattu A, Kolodecik T, Pandol SJ, Gorelick F. Ethanol exposure depletes hepatic pigment epithelium-derived factor, a novel lipid regulator. Gastroenterology. 2009; 136:331-40.e2

113. Chung C, Doll JA, Gattu AK, Shugrue C, Cornwell M, Fitchev P, Crawford SE. Anti-angiogenic pigment epithelium-derived factor regulates hepatocyte triglyceride content through adipose triglyceride lipase (ATGL). J Hepatol. 2008:48:471-8.

114. Jenkins AJ, Zhang SX, Rowley KG, Karschimkus CS, Nelson CL, Chung JS, O'Neal DN, Januszewski AS, Croft KD, Mori TA, et al. Increased serum pigment epithelium-derived factor is associated with microvascular complications, vascular stiffness and inflammation in type 1 diabetes. Diabet Med. 2007;24:1345-51.

115. Yin L, Wu X, Gong Y, Shi Y, Qiu Y, Zhang H, Liu X, Gu Q. OX-LDL upregulates the vascular endothelial growth factor-to-pigment epitheliumderived factor ratio in human retinal pigment epithelial cells. Curr Eye Res. 2011;36:379-85

116. Wen H, Liu M, Liu Z, Yang X, Liu X, Ni M, Dong M, Luan X, Yuan Y, Xu X, et al. PEDF improves atherosclerotic plaque stability by inhibiting macrophage inflammation response. Int J Cardiol. 2017;235:37-41.

117. Schonbeck U, Libby P. CD40 signaling and plaque instability. Circ Res. 2001; 89:1092-103.

118. Takenaka K, Yamagishi S, Matsui T, Nakamura K, Imaizumi T. Role of advanced glycation end products (AGES) in thrombogenic abnormalities in diabetes. Curr Neurovasc Res. 2006:3:73-7.

119. Qiu F, Zhang H, Yuan Y, Liu Z, Huang B, Miao H, Liu X, Zhao Q, Zhang H,

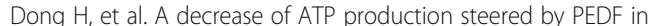
cardiomyocytes with oxygen-glucose deprivation is associated with an AMPK-dependent degradation pathway. Int J Cardiol. 2018;257:262-71.

120. Gao X, Zhang H, Zhuang W, Yuan G, Sun T, Jiang X, Zhou Z, Yuan H, Zhang Z, Dong H. PEDF and PEDF-derived peptide 44mer protect cardiomyocytes against hypoxia-induced apoptosis and necroptosis via anti-oxidative effect. Sci Rep. 2014;4:5637.

Ready to submit your research? Choose BMC and benefit from:

- fast, convenient online submission

- thorough peer review by experienced researchers in your field

- rapid publication on acceptance

- support for research data, including large and complex data types

- gold Open Access which fosters wider collaboration and increased citations

- maximum visibility for your research: over $100 \mathrm{M}$ website views per year

At $\mathrm{BMC}$, research is always in progress.

Learn more biomedcentral.com/submissions 